\title{
CONCENTRATIE EFFECTENBEZIT EN DE INVLOED DAARVAN OP DE KOERSVORMING TER BEURZE
}

\author{
Drs. J. Soutendijk
}

In dit artikel zullen wij allereerst trachten een $k$ wantitatieve benadering te geven van de concentratie van effectenbezit en de verschuivingen, die daarin optreden. Daarna zal de invloed op de koersvorming en op de keuze van de beleggingen worden behandeld.

\section{Concentratie effectenbezit}

Zoals bekend kunnen de bezitters van effecten worden onderverdeeld in de groepen particulieren en instellingen. Ons interesseert in dit bestek in de allereerste plaats het effectenbezit van instellingen. Ruwweg kan men de instellingen onderverdelen in

A. Institutionele beleggers

B. Beleggingsmaatschappijen

C. Overige instellingen (w.o. ondernemingen en private instellingen zoals bijv. liefdadige instellingen, kerken e.d.).

Van groep $\mathrm{C}$ is geen statistisch materiaal voorhanden. Men krijgt de indruk, dat deze groep kwantitatief gezien veel minder belangrijk is dan de groepen $\mathrm{A}$ en $B$ waarover wel gegevens beschikbaar zijn, zij het dat in enkele gevallen moet worden volstaan met ramingen.

In tabel A wordt een overzicht gegeven van de totale beleggingen alsmede die in aandelen en obligaties van Nederlandse institutionele beleggers en beleggingsmaatschappijen in de jaren 1953, 1957 en 1961. (Over latere jaren zijn nog geen vergelijkbare cijfers gepubliceerd.)

Men ziet uit de tabel, dat Nederlandse beleggingsfondsen vrijwel uitsluitend in aandelen beleggen maar dat aandelen (1961 3\% ) slechts een zeer klein deel uitmaken van de totale beleggingen van Nederlandse institutionele beleggers. Bij deze laatste groep waren de belangrijkste beleggingsvormen in 1961: onderhandse leningen op lange termijn, obligaties en hypotheken. Hoewel aandelen een gering percentage uitmaken van de totale beleggingen van institutionele beleggers is er van 1953 tot 1961 toch wel een relatieve stijging waar te nemen terwijl daarentegen de obligaties verhoudingsgewijs onbelangrijker zijn geworden. Aangenomen mag worden dat het totale belang in aandelen nog meer is toegenomen dan de cijfers aangeven omdat de aandelen doorgaans conservatief zijn gewaardeerd. Het is namelijk veelal gebruikelijk om de aandelen op de balans te zetten voor de aankoopwaarde of voor de beurswaarde als deze lager is. De aankoopwaarde is in het merendeel der gevallen lager dan de beurswaarde en wel met name bij verscheidene aandelen, die reeds geruime tijd deel uitmaken van de portefeuille. Deze discrepantie tussen boekwaarde en beurswaarde is daarentegen bij onderhandse leningen, obligaties en hypotheken geheel of vrijwel geheel te verwaarlozen. 
Totaal beleggingen van Nederlandse institutionele beleggers en beleggingsfondsen in effecten

\begin{tabular}{cccc}
\hline $\begin{array}{c}\text { Institutionele } \\
\text { beleggers }\end{array}$ & $\begin{array}{c}4 \text { grootste beleggings- } \\
\left.\text { fondsen }{ }^{1}\right)\end{array}$ & Totaal \\
\hline $\begin{array}{c}\text { Bedrag } \% \text { van } \\
(\times f \text { mln. })\end{array}$ & totale bel. $(\times f$ mln. $)$ & totale bel. $(\times f$ mln. $)$ & totale bel. \\
\hline
\end{tabular}

Aandelen

1953

1957

420

2.2

272

98

692

3.7

553

2.2

464

95

1.017

3.9

1961

1.193

3

1.716

99

2.909

7

Obligaties

1953

6.244

34.1

1957

7.827

30.7

1
3
7

$\frac{-}{1}$

6.245

33.6

1961

10.765

27.2

7.830

30.1

10.772

26.1

Totaal beleggingen ${ }^{2}$ )

1953

18.311

1957

25.493

100

278

100

18.589

100

1961

39.561

100

487

100

25.980

100

100

1.725

100

41.286

100

2) Het totaal van deze 4 beleggingsfondsen maakte in 1961 naar schatting $\pm 90 \%$ van het totaal van alle Nederlandse beleggingsfondsen uit.

$\left.{ }^{2}\right)$ Inclusief overige soorten beleggingen zoals bijv, onderhandse leningen, hypotheken, onroerend goed e.d.

Men ziet uit tabel B, dat eigenlijk alleen Pensioenfondsen en Levensverzekeringsmaatschappijen een niet geheel te verwaarlozen bedrag in aandelen beleggen. De belegging in aandelen bij de overige institutionele beleggers is onbetekenend of nihil (bij de Girodiensten). Deze beperking van het belang bij aandelen door deze groepen van institutionele beleggers is zeer begrijpelijk als men in aanmerking neemt, dat bijv. Pensioenfondsen en Levensverzekeringsmaatschappijen verplichtingen in guldens aangaan, waarvan de vervulling in gevaar zou kunnen komen bij een aanzienlijke koersdaling van aandelen. Voor Spaarbanken en de Girodiensten geldt dat een groot deel van de gelden op korte termijn is uitgezet weshalve belegging in aandelen afgezien nog van koersrisico's slechts voor een gedeelte der toevertrouwde middelen in aanmerking komt. Het is dan ook niet verwonderlijk, dat voor Spaarbanken, Girodiensten en voor Sociale Instellingen strenge wettelijke voorschriften bestaan met betrekking tot de belegging in aandelen. Levensverzekeringsmaatschappijen en Pensioenfondsen vallen onder de jurisdictie van de Verzekeringskamer, die richtlijnen kan geven voor de beleggingen. Hoewel Levensverzekeringsmaatschappijen en Pensioenfondsen zowel krachtens hun aard als ook in verband met het ontbreken van strenge wettelijke voorschriften veel vrijer zijn dan de overige genoemde institutionele beleggers is de belegging in aandelen nog steeds van zeer bescheiden omvang gebleven. 
Tabel B Gespecificeerde beleggingen van Nederlandse institutionele beleggers in effecten $(\times f \mathrm{mln}$.)

\begin{tabular}{|c|c|c|c|c|c|c|c|c|}
\hline 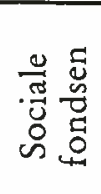 & 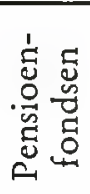 & 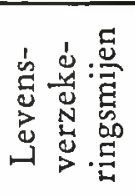 & 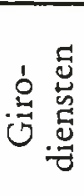 & $\begin{array}{l}\text { ज. } \\
\text { م }\end{array}$ & 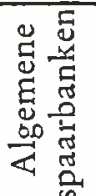 & 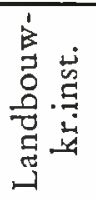 & $\begin{array}{l}\overrightarrow{\tilde{y}} \\
\stackrel{4}{4}\end{array}$ & 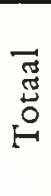 \\
\hline
\end{tabular}

Aandelen

$\begin{array}{llllllrrrr}1953 & \left.34^{1}\right) & 156 & 197 & - & 20 & 8 & 6 & - & 420 \\ 1957 & 18 & 248 & 223 & - & 20 & 15 & 28 & 1 & 553 \\ 1961 & 18 & \left.644^{2}\right) & 416 & - & 27 & 64 & 20 & 4 & 1.193\end{array}$

Obligaties

$\begin{array}{rrlrrrrrrr}1953 & 716 & 1.977 & 1.293 & 366 & 695 & 730 & 466 & - & 6.244 \\ 1957 & 842 & 2.649 & 1.193 & 478 & 847 & 1.112 & 693 & 13 & 7.827 \\ 1961 & 1.122 & \left.3.661^{2}\right) & 1.452 & 597 & 1.014 & 1.797 & 1.096 & 26 & 10.765\end{array}$

Totaal beleggingen institutionele beleggers

$\begin{array}{llllllllll}1953 & 1.911 & 5.188 & 4.575 & 1.145 & 1.659 & 1.458 & 2.374 & - & 18.311 \\ 1957 & 2.416 & 7.461 & 6.672 & 1.193 & 2.241 & 2.214 & 2.962 & 334 & 25.493 \\ 1961 & 3.300 & \left.12.256^{2}\right) & 9.688 & 1.769 & 3.197 & 3.556 & 5.288 & 507 & 39.561\end{array}$

1) Inclusief enkele fondsen die later uit de statistiek zijn genomen of naar de Pensioenfondsen zijn overgebracht.

$\left.{ }^{2}\right)$ Inclusief 155 eigen risicodragende pensioenfondsen; in 1953 en 1957 waren dit er slechts 55.

Geringe belangstelling van levensverzekeringsmaatschappijen en pensioenfondsen voor aandelen

Men kan zich overigens afvragen of belegging in aandelen bij deze laatste twee groepen niet een veel te geringe plaats inneemt. Weliswaar ondervindt men bij aandelenbelegging in relatief sterke mate de invloed van koersfluctuaties, maar daar staat tegenover dat men zich via de belegging in aandelen grotendeels kan onttrekken aan de daling van de koopkracht en bovendien kan profiteren van de economische groei.

De daling van de koopkracht valt allerminst te onderschatten. Deze bedroeg in de periode 1953/63 in een aantal landen gemiddeld als volgt:

$\begin{array}{lrr}\text { Nederland } & \text { bijna } 3 \% & \text { per jaar } \\ \text { West-Duitsland } & \text { bijna } 2 \% & \text { per jaar } \\ \text { Frankrijk } & \text { ruim } 4 \% & \text { per jaar } \\ \text { Italië } & 3 \% & \text { per jaar } \\ \text { Groot-Brittannië } & 21 / 2 \% \text { per jaar } \\ \text { Verenigde Staten } & \text { bijna } 1 \frac{1}{2} \% \text { per jaar }\end{array}$

Ook voor de komende jaren moet ernstig rekening worden gehouden met een verdere koopkrachtdaling, in aanmerking genomen dat een zekere mate van inflatie een aanvaard verschijnsel is geworden in de meeste Westerse landen.

Daarnaast is ook de economische groei een belangrijke faktor. Voor de jaren tot 1970 wordt voor de O.E.E.C.-landen een gemiddelde jaarlijkse toeneming van het bruto nationale produkt van $4 \%$ verwacht.

Wanneer wij terugzien op het tijdvak 1953/63 dan zien wij, dat in deze 
periode het algemeen A.N.P.-C.B.S.-indexcijfer van aandelenkoersen is gestegen van 100 naar \pm 400 terwijl degenen, die in dit tijdvak in obligaties hadden belegd slechts hun vermogen in guldens ongeveer op peil hebben kunnen houden. $\mathrm{Zij}$ konden dus geen dekking vinden tegen de waardedaling van het geld en slaagden er ook niet in om te profiteren van de economische groei. Men mag voor de komende jaren zeker niet een dergelijke fraaie koersstijging voor aandelen verwachten als van 1953 tot 1963, maar dit neemt niet weg, dat men met de stringente toepassing van de "gulden is gulden"-leer bij een belegging op lange termijn steeds verder achterop raakt.

\section{Aandelenbezit institutionele beleggers en beleggingsfondsen in verbouding tot totale beurswaarde}

Wij zullen nu de beleggingen in aandelen van de gezamenlijke institutionele beleggers en beleggingsfondsen in verband brengen met het totaal van de beleggingen in Nederlandse aandelen, waarbij dus ook de beleggingen van de overige instellingen en van particulieren zijn inbegrepen. Voor dit doel kan worden volstaan met een globale benadering. Bij gebrek aan gegevens over aandelen die niet ter beurze zijn genoteerd kan men het beste de beleggingen van beleggingsfondsen en institutionele beleggers vergelijken met de totale beurswaarde van alle ter beurze van Amsterdam genoteerde fondsen. Overigens zijn de beleggingen van institutionele beleggers en beleggingsfondsen in de zgn. incourante aandelen verhoudingsgewijze toch vrij onbelangrijk, zodat onze beperking tot de op de beurs genoteerde aandelen niet zo'n groot bezwaar vormt.

De Nederlandse institutionele beleggers beleggen hun gelden voor het overgrote deel in Nederlandse aandelen. Ter vergelijking met de beurswaarde van Nederlandse aandelen zou men hierbij eigenlijk de belangen van buitenlandse institutionele beleggers in Nederlandse aandelen op moeten tellen. Van deze vermoedelijk onbelangrijke groep zijn echter geen gegevens bekend. Ter vereenvoudiging is daarom maar uitgegaan van het (gedeflatteerde) bedrag van de beleggingen van Nederlandse institutionele beleggers in Nederlandse aandelen (in $1961 f 1.056 \mathrm{mln}$.). Aangezien evenwel de beurswaarde veel hoger is dan de balanswaarde moet dit bedrag nog worden verhoogd met het geraamde verschil tussen beide waarden. Sinds 1962 worden hierover gegevens gepubliceerd. In dat jaar was de beurswaarde ruim $60 \%$ hoger dan de balanswaarde. Wij nemen aan dat dit verschil in 1961 toch ook wel minstens 60\% bedroeg omdat in 1961 het algemene koerspeil hoger was dan in 1962. Men kome dan tot een totaal van $f 1.056+60 \%$ van $f 1.056=f 1.690 \mathrm{mln}$.

$\mathrm{Bij}$ de beleggingsfondsen doet zich een dergelijk schattingsprobleem voor. In tabel A werden de totale beleggingen (incl. de buitenlandse) van Nederlandse beleggingsfondsen vermeld. Ter vergelijking met de beurswaarde van Nederlandse aandelen moeten wij echter deze buitenlandse beleggingen (1961 $\pm f 970$ mln.) eraf trekken maar anderzijds moet opgeteld worden het belang van buitenlandse beleggingsfondsen in Nederlandse aandelen. Aangenomen mag worden, dat dit laatste bedrag aanzienlijk groter is dan de vorengenoemde $f 970 \mathrm{mln}$. Omstreeks oktober 1963 zouden Amerikaanse beleggingsfondsen alleen al in Koninklijke Petroleum en Philips $\pm f 1.400 \mathrm{mln}$. hebben belegd. Hierbij komen nog de belangen van Amerikaanse beleggingsfondsen in overige Nederlandse 
aandelen alsmede de beleggingen van beleggingsfondsen uit andere landen in Nederlandse aandelen. Wij weten niet of de cijfers van 1961 veel afwijken van die van 1963, maar het lijkt toch wel zeer waarschijnlijk dat buitenlandse beleggingsfondsen in 1961 minstens $f 1.500 \mathrm{mln}$. in Nederlandse aandelen hadden belegd. Bij deze $f 1.500 \mathrm{mln}$. moeten wij optellen de beleggingen van binnenlandse beleggingsfondsen. Deze bedroeg $\pm f 745 \mathrm{mln}$. (het totaal van de 4 grootste beleggingsfondsen) $+f 75 \mathrm{mln}$. (schatting overige beleggingsfondsen) $= \pm f 820 \mathrm{mln}$. Totaal dus $\pm f 2.320 \mathrm{mln}$. Nederlandse aandelen in handen van beleggingsfondsen.

Tabel C

2

Geschatte beurswaarde bezit Nederlandse aandelen
Totale beurswaarde Nederlandse aandelen $\left.{ }^{1}\right) \quad 2$ in $\%$ van 3

( $\times f$ mln., per ultimo 1961)

Institutionele

beleggers

Beleggingsfondsen

1) Genoteerd ter beurze van Amsterdam.

Het percentage van 13,2 geeft ons ter benadering toch wel enig houvast. Wij zullen er niet ver naast zijn als wij stellen, dat naar beurswaarde gerekend 10 à $15 \%$ van de Nederlandse ter beurze genoteerde aandelen per ultimo 1961 in het bezit was van institutionele beleggers en beleggingsfondsen.

\section{Invloed concentratie op de koersworming}

Institutionele beleggers en beleggingsmaatschappijen hebben tezamen een groot deel van de Nederlandse obligaties in bezit, maar daarentegen een veel kleiner gedeelte $(10$ a $15 \%)$ van de Nederlandse aandelen. Hoe is nu de invloed op de koersvorming ter beurze? Wij beschikken niet over gegevens om te kunnen beoordelen of de omloopsnelheid van effecten in het bezit van deze twee groepen groter of kleiner is dan bij de rest van de beleggers (vooral particulieren). Voor aandelen geldt, dat particulieren veel nerveuzer reageren op berichten en dus sneller geneigd zijn te kopen of te verkopen. Daarentegen valt op te merken, dat particulieren over het algemeen langer blijven zitten op aandelen waar minder spectaculaire dingen mee gebeuren dan de op lange termijn dynamischer ingestelde beleggingsfondsen. Ondanks onvoldoende exacte kennis op dit terrein lijkt de veronderstelling gewettigd, dat beleggingsfondsen en institutionele beleggers gezamenlijk nog steeds een vrij matig gedeelte van de totale beurshandel in aandelen uitmaken, in tegenstelling tot de obligatiemarkt, waar de invloed van institutionele beleggers zeer groot is.

Men hoort veelal de mening verkondigen dat de koersvorming van aandelen dikwijls door beleggingsfondsen e.d. in ongunstige zin wordt beïnvloed verge- 
leken met een beurs waar uitsluitend particulieren verhandelen. Men hoort dit bezwaar echter zelden met betrekking tot de handel in obligaties, die een veel rustiger verloop heeft.

Er wordt soms gesteld, dat vele aandelen met name door het optreden van beleggingsfondsen, in vaste handen zitten waardoor er naar verhouding minder materiaal aan de markt komt dan bijv. vóór de oorlog het geval was. Op een dergelijke „dunne” markt zouden de koersfluctuaties groter kunnen zijn. Opgemerkt kan echter worden, dat het in verband met het vorenstaande allerminst vaststaat, dat er door het optreden van beleggingsfondsen een dunnere markt komt. Maar ook al zou dit het geval zijn, dan is het nog niet zeker, dat er inderdaad grotere koersfluctuaties optreden. Een voorbeeld moge dit verduidelijken.

Geval $A$ Op één dag worden 10 stuks van een aandeel verhandeld, uitsluitend door particulieren. Er komt een ongunstig bericht, hetwelk tot gevolg heeft, dat er bij dezelfde koers de volgende dag tweemaal zoveel aanbieders en de helft van de vragers zouden optreden, d.i. dus 20 aanbieders en 5 vragers. Dit kan natuurlijk in werkelijkheid niet, de prijs zakt en er komt cen nieuw evenwicht tot stand, bijv. bij een omzet van 10 of 8 stuks.

Geval $B$ Door de invloed van de institutionele beleggers treedt een verdunning van de markt op en er wordt slechts 1 stuk verhandeld. Stel er komt ook in dit geval een slecht bericht, waardoor het aanbod evenals in geval A verdubbelt. $\mathrm{Nu}$ hangt het maar helemaal af van de reactie van die ene vrager of hij weg blijft of niet na het vernemen van het slechte bericht. Blijft hij inderdaad weg, wat in vele gevallen zal voorkomen, dan staat er tegenover een aanbod van 2 geen vraag, waardoor er cen veel lagere (laat)koers kan ontstaan. Het is echter ook denkbaar, dat deze vrager zich niet terugtrekt en in dat geval staan er 2 aanbieders tegenover vrager $(2: 1)$. Dan ligt de verhouding gunstiger dan in geval $\mathrm{A}$ (verhouding $4: 1)$.

Uit deze voorbeelden blijkt dus, dat er in een dunne markt niet altijd grotere koersfluctuaties behoeven op te treden dan op een markt met veel vraag en aanbod.

Men kan het over een andere boeg gooien en stellen, dat beleggingsfondsen zulke grote pakketten van bepaalde aandelen bezitten, dat de totale verkoop daarvan wel een enorme koersdrukkende invloed moet hebben. Nu mag men rustig aannemen, dat beleggingsfondsen, geholpen door hun eigen ervaring en die van de banken en commissionairs die hun stukken verhandelen, de markt niet forceren en hun verkopen over een langere periode uitstrekken. Dit neemt echter niet weg, dat er bijv. over een half jaar of een jaar bezien wel degelijk een aanzienlijke koersdruk kan ontstaan. Het zou echter onjuist zijn te veronderstellen, dat er bij verhandeling enkel en alleen door particulieren (hetgeen overigens al lang verleden tijd is) niet een zodanige koersdruk zou optreden. Integendeel. Wanneer bijvoorbeeld een beleggingsmaatschappij op grond van bestudering van een specifieke onderneming (Q), tot de conclusie komt dat het belang bij onderneming $Q$ geliquideerd moet worden, dan zal zij deze liquidatie uitsmeren waardoor ceteris paribus de koers geleidelijk daalt. Het is zeer wel mogelijk, dat andere beleggingsfondsen tot dezelfde conclusie komen en dienovereenkomstig handelen. Krijgt daarentegen het publiek vroeg of laat 
hetzelfde inzicht als de beleggingsmaatschappij - bijv. na publikatie van een krantenbericht of door af te kijken wat de beleggingsmaatschappij doet - dan kan men er verzekerd van zijn, dat deze beleggers veel nerveuzer zullen reageren en dat de kans op het ,smijten" van aandelen lang niet uitgesloten is, waardoor de schok des te harder aankomt. In dergelijke gevallen kan er dus een gunstige stabiliserende invloed uitgaan van beleggingsfondsen.

Toch kunnen wij ons wel gevallen indenken, waarin beleggingsfondsen een ongunstige invloed hebben op de koersvorming. Stel bijvoorbeeld dat een beleggingsfonds op grond van een analyse besluit tot verkoop van de aandelen van een specifieke onderneming. Wanneer andere beleggingsfondsen en de overige beleggers niet dezelfde visie hebben dan kan er een koersdruk ontstaan, die ten nadele werkt van de overblijvende bezitters van de desbetreffende aandelen. Dergelijke gevallen doen zich echter veel minder voor dan de grillige koersfluctuaties, die ontstaan door mededelingen en geruchten. Het komt nogal eens voor, dat bepaalde bedrijfstakken ineens in de belangstelling komen te staan. Men ziet heel dikwijls dat dan alle ondernemingen binnen een branche profiteren van de vergrote belangstelling. Daarbij zijn goede en slechte ondernemingen en daarbij zijn ook ondernemingen die uit hoofde van hun produktieprogramma in het geheel niet of slechts zijdelings zouden kunnen profiteren van een gunstige faktor zoals bijvoorbeeld de aardgasvondst in Nederland. Later volgt dan de teleurstelling en verscheidene koersen dalen weer. Voor dergelijke veel meer voorkomende fluctuaties moet men vrijwel altijd particulieren aansprakelijk stellen en niet de beleggingsfondsen.

\section{Invloed concentratie aandelenbezit op de keuze van beleggingen}

Verwacht mag worden, dat in de komende jaren het gezamenlijke aandelenbezit van beleggingsfondsen en institutionele beleggers aanzienlijk zal toenemen. De beleggingsfondsen hebben een stormachtige groei achter de rug en het ziet er naar uit dat ook in de toekomst de belangstelling voor deze instellingen nog sterk zal toenemen. Deze verwachting is gegrond op de veronderstelling dat wij nog vrijwel aan het begin staan van de popularisering van het effectenbezit, die met name via beleggingsfondsen tot stand wordt gebracht. In dit verband valt o.a. te memoreren de mogelijkheid, die onlangs is geschapen om via het Beleggingsfonds voor Spaarders (creatie van de Nederlandse Spaarbankbond) in aandelen Robeco te beleggen.

Institutionele beleggers hebben nog slechts een zeer gering belang in aandelen. Met het oog op de koopkrachtdaling en de welvaartsstijging lijkt het waarschijnlijk, dat dit belang ondanks de daaraan verbonden risico's in de toekomst zal worden vergroot, zij het dat dit proces zich vermoedelijk slechts langzaam zal voltrekken.

Totaal bezien lijkt het ons aannemelijk, dat de voor risicodragende belegging te bestemmen gelden via deze twee groepen van instellingen sneller zullen toenemen dan de beschikbare beleggingsmogelijkheden in Nederland. Dit houdt in, dat of het relatieve belang in Nederlandse aandelen zal worden vergroot óf dat er een verschuiving naar belegging in het buitenland zal moeten plaatsvinden. Voorzover het eerste geval zich zal voordoen zullen o.i. niet te onderschatten beleggingsproblemen ontstaan. Het gevaar is namelijk lang niet denkbeeldig, dat 
de beleggingsfondsen, die doorgaans slechts een bescheiden gedeelte (bijv. maximaal $5 \%$ ) van het aandelenkapitaal van een onderneming willen bezitten, door de grote toevloed van risicodragende middelen a.h.w. getrokken zullen worden naar ondernemingen van mindere kwaliteit en naar ondernemingen waarvan de aandelen zeer incourant zijn, waardoor de selectie en de flexibiliteit ${ }^{1}$ ) van de beleggingspolitiek aanzienlijk zouden kunnen worden verkleind. Het alternatief is dus belegging in het buitenland, maar dit stelt zeer hoge eisen aan de spankracht van de beleggingsresearch. Het is namelijk al zeer moeilijk om een gebied van 1000 ondernemingen goed te overzien maar de problemen worden nog veel groter als dit aantal zou worden verveelvoudigd. Men moet in dit verband niet vergeten, dat bij belegging in het buitenland veel meer moet worden gesteund op kennis uit de tweede hand.

\section{Conclusie}

Samenvattend kan worden gesteld, dat de optredende verschuiving van aandelenbezit in de richting van beleggingsfondsen en institutionele beleggers geleidelijk verloopt en eerder een gunstige dan een ongunstige invloed uitoefent op de koersvorming ter beurze. De grote toevloed van middelen naar deze instellingen (dit geldt met name voor de beleggingsfondsen) schept evenwel belangrijke beleggingsproblemen omdat men versnippering en belegging in tweederangs aandelen moet trachten te voorkomen en in verband daarmede het oog veel meer dan voorheen op het buitenland zal moeten richten, hetgeen echter uit het oogpunt van overzichtelijk heid zeer zware eisen stelt.

1) Zie ook Dr. M. P. Gans in „Beleggingsleer en Beleggingsfondsen” (Bedrijfseconomische Monografieën, deel 26, blz. 122 e.v., Leiden 1957) 